\title{
JAEXÁ VA'E JO HETE RE \\ "O CORPO QUE ENXERGAMOS"
}

Sophia Ferreira Pinheiro ${ }^{1}$

O início dessa pesquisa é como uma gota de aquarela dentro de um copo d'água, imersa em ambiente fecundo, penetra suavemente cada micro espaço líquido. Cheia de expansão, descobertas e possibilidades de um campo que flui. $\mathrm{Na}$ dança da cor em movimento, formam-se imagens rítmicas e eu como artista e antropóloga em formação, sei bem da importância dessa cor fluída para minha paleta que metaforicamente - é essa pesquisa. Depois de muito esboço, segui o ritmo e me deixei conduzir. Na pesquisa, pretendo tratar da trajetória e produções imagéticas da indígena cineasta, Mbyá-Guarani, Patrícia Ferreira Pará Yxapy a partir das múltiplas relações que criamos - eu e ela - através das imagens ${ }^{2345}$.

Patrícia mora na Aldeia Ko'enju, em São Miguel das Missões, estado do Rio Grande do Sul, onde é professora desde 2006. Em 2017 comemora-se 10 anos da primeira oficina do projeto Vídeo Nas Aldeias (VNA) em Ko'enju, mesmo ano em que co-fundou o Coletivo Mbyá-Guarani de Cinema. Atualmente Patrícia é a mulher indígena mais atuante do VNA e está finalizando seu primeiro longa metragem autoral. Já realizou os filmes: As Bicicletas de Nhanderu, 2011/45min; Desterro Guarani, 2011/38min; TAVA, a casa de pedra, 2012/78min e No caminho com Mario, 2014/20min. Nas palavras de Patrícia sobre alguns dos motivos que a levaram a usar as câmeras:

\footnotetext{
${ }^{1}$ Universidade Federal de Goiás, Brasil.

${ }^{2}$ Tradução em Mbyá-Guarani por Patrícia Ferreira Pará Yxapy.

${ }^{3}$ Neste ensaio visual, o corpo é uma referência ao corpo da câmera e ao corpo feminino.

${ }^{4}$ Esta obra é um dos resultados poéticos de minha pesquisa de mestrado, em fase de conclusão: A imagem como arma: Apropriação, olhares e resistência na produção imagética da cineasta indígena Patrícia Ferreira Pará Yxapy. Título ainda provisório. Pesquisa com orientação da profa. Dra. Maria Luiza Rodrigues Souza.

${ }^{5}$ Sei que as imagens não criam relações sozinhas, acreditar nisso seria uma ingenuidade essencializante dentro um processo que acredito ser retroalimentar: criamos relações - produzimos imagens; nos conhecemos a partir das imagens (a primeira vez que a "vi" foi quando assisti à um de seus filmes), criamos imagens juntas - nos relacionamos. E assim seguimos em movimentos não lineares.
} 
Eu tenho as minhas respostas para a pergunta de várias pessoas: o motivo que me levou a usar as câmeras. Trabalhar com audiovisual (estar junto com os meninos do coletivo), sendo mulher indígena, e além de trabalhar como uma professora na escola, a resposta é simples:primeiro, dar minha pequena contribuição e acompanhar as lutas diárias das nossas lideranças indígenas; para provocar os espectadores sejam indígenas ou não-indígenas e também nos motivar, nos inspirar a produzir nossos próprios Vídeos, documentários, entre outros; sermos autores das nossas próprias histórias, onde podemos falar sobre nossas vivências, experiências, problemas e que possamos trocar informações e visões sobre cultura indígena e identidade indígena no Brasil e no mundo (...) Mostrar para os não-indígenas que acreditam naquela velha história do índio "congelado”, que nós aparecemos somente na História da época do Caminha e dos jesuítas, dizer que nós não ficamos congelados em 1500 , que nós estamos em 2016 e precisamos urgentemente falar sobre nós indígenas atuais e dizer que nós não somos folclore como contam nos livros de História do Brasil. Para pensar e refletir sobre a nossa própria história. E assim, quebrar um pouco aquelas coisas-ruins que a gente escuta por aí das pessoas ignorantes que falam com seus comentários ou críticas preconceituosas quando a questão é indígena.

O cinema indígena é heterogêneo. São muitos povos com linguagens, demandas e produções específicas. Utilizar a câmera como uma forma de arma de luta e resistência tem sido umas das grandes potências do movimento indígena contemporâneo. Sejam em produções para a própria aldeia como uma forma de documentar/guardar práticas culturais, seja como registro político de alguma atividade da militância indígena e do uso da imagem como documento ${ }^{6}$, seja com o uso particular da câmera ${ }^{7}$, seja como experimento, seja como cinema. A produção do saber e o deslocamento de poder que essa outra maneira de pegar a câmera e olhar através dela provoca é desestabilizador para a concepção de imagem, representações e dos formatos acadêmicos e técnicos das realizações de imagens ocidentais.

Com um recorte de gênero, o que Patrícia e outras realizadoras indígenas produzem vai além da própria linguagem cinematográfica/artística. Assim como não é “o branco" que representa ao indígena, não é o homem indígena que representa a mulher indígena, mas é ela que se faz agora como elemento ativo e não mais passivo dessas produções. Frequentemente é atribuído à mulher o lugar de indivíduo passivo em relação ao fazer artístico, relação ativa/passiva. Atribui-se ao que Laura Mulvey no artigo Prazer Visual e Cinema Narrativo (1975) discorre da mulher como imagem e do homem enquanto portador da câmera. Claro que no contexto indígena essas relações de gênero são muito mais complexas. Mas como indaga Ivana Bentes em texto publicado

\footnotetext{
${ }^{6}$ No âmbito do direto, da prova de atentados feitos por fazendeiros ou na comprovação de algum acordo.

${ }^{7}$ Utilizado principalmente nas redes sociais.
} 
em 2004 nos arquivos do VNA, "o lugar do realizador é um lugar de poder. E isso fica claro na pergunta: por que só homens filmam? São poucas as realizadoras indígenas." 8

O número reduzido de mulheres realizadoras parece indicar uma possível dificuldade das mulheres indígenas ${ }^{9}$, ao se apropriarem de uma atividade "artística" para além das destinadas às suas dinâmicas tradicionais. Tendo em vista que ao ser designada para tal realização, agrega-se também a ela uma maneira de status - político e social - na relação de convívio da aldeia, no caso das mulheres indígenas (Turner, 1993). Portanto, usar a câmera é portar-se de uma forma de poder, é adquirir, como salienta Turner, um status social e político, ou seja, no limite, portar a câmera é também assumir um papel de liderança.

A linguagem artística cinematográfica possibilita tal narrativa híbrida de histórias potenciais autobiográficas e potencialmente apropriadas de seus discursos. As produções imagéticas pelas/pelos indígenas registram memórias e podem ser instrumentos potentes de resistência cultural. "Há muitas posições de sujeito que devemos ocupar; não se é apenas uma coisa" (Spivak, 1990: 60). O meu discurso é passível de críticas e reformulações, mas diante do contexto atual que os povos indígenas enfrentam no Brasil, as produções culturais emergentes, realizadas principalmente pelas mulheres indígenas, é o começo de uma relevante trajetória da cultura visual brasileira. Este é só o início, uma tela em branco, à espera das imagens e seus movimentos vivos.

Como dito, a utilização e a reinvenção da linguagem audiovisual para suas próprias demandas é poder. Poder enquanto capacidade e possibilidade de agir e falar. Poder enquanto autoridade. Poder da invenção, produto da experiência coletiva. Poder para as mulheres indígenas. "As relações são antes de tudo combativas" (Geertz, 1997). Esse poder e seus campos simbólicos podem romper com os silenciamentos e as opressões resultantes das marginalizações impostas às mulheres indígenas? A relação entre eu e Patrícia é estabelecida, a cada dia, a cada imagem, a cada processo criativo compartilhado entre nós duas. Assim como este ensaio fotográfico é.

Esta série fotográfica foi realizada na Cidade de Goiás (GO) em 2016 e gestada durante um almoço, em uma das nossas conversas criativas. Tirei as fotografias com Patri num quarto de hotel, utilizando uma câmera de celular e a filmadora emprestada

8 BENTES, Ivana. Câmera muy very good pra mim trabalhar. Disponível em: < http://www.videonasaldeias.org.br/2009/biblioteca.php?c=11 . Acessado em 23 de Setembro de 2014.

${ }^{9} \mathrm{E}$ de mulheres negras e mulheres brancas, cada qual com seu recorte social. 
por uns amigos. Na ocasião, Patri estava na cidade para ser júri de uma das mostras do FICA 2016 - Festival Internacional de Cinema Ambiental. Depois das fotos impressas, fiz intervenções em aquarela e giz pastel seco e oleoso sobre elas, tentando expressar um pouco da espiritualidade Mbyá a partir do meu olhar artístico.

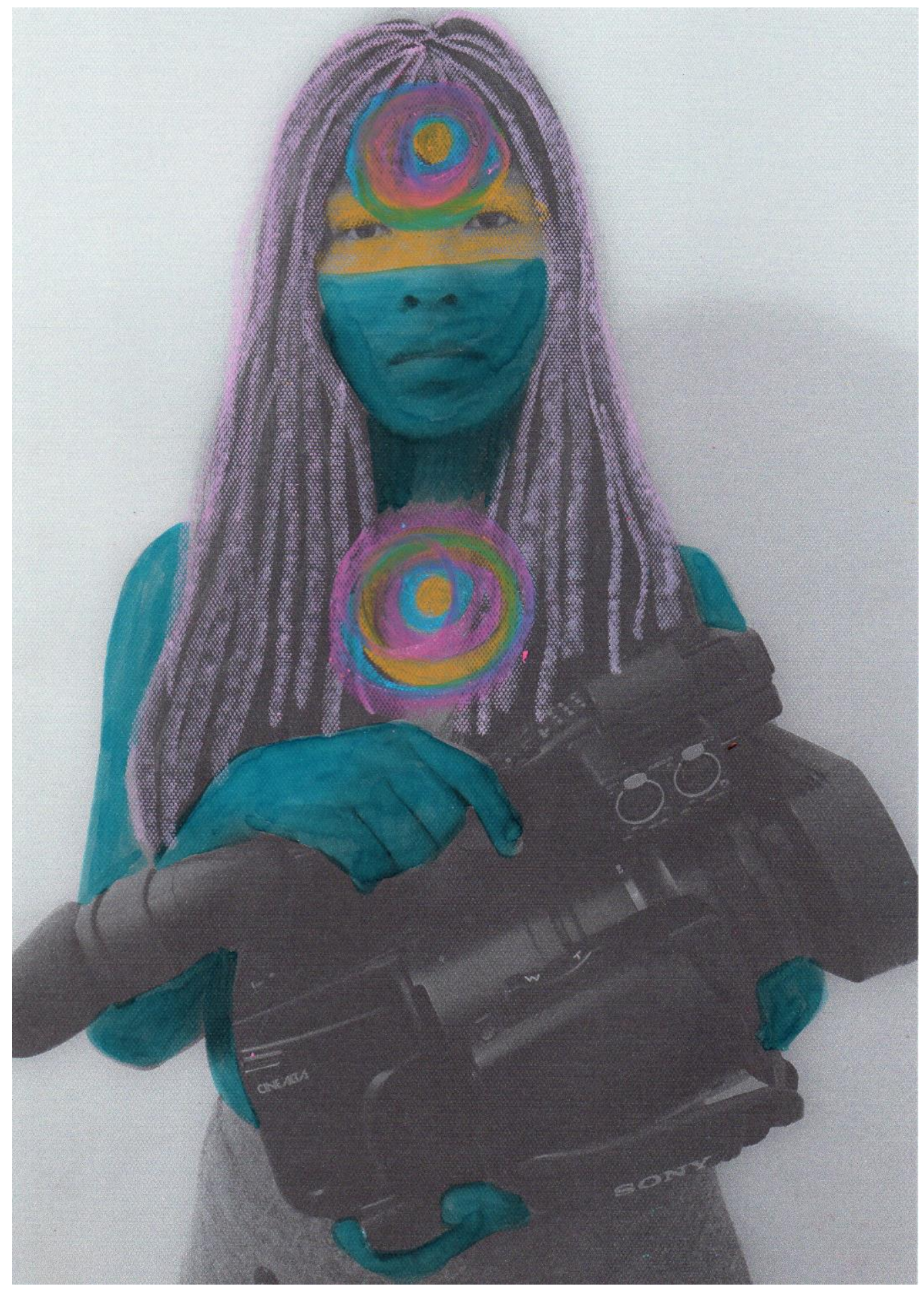

“pará yxapy e seus corpos”

Iluminuras, Porto Alegre, v. 18, n. 43, p. 361-367 jan/jul, 2017. 


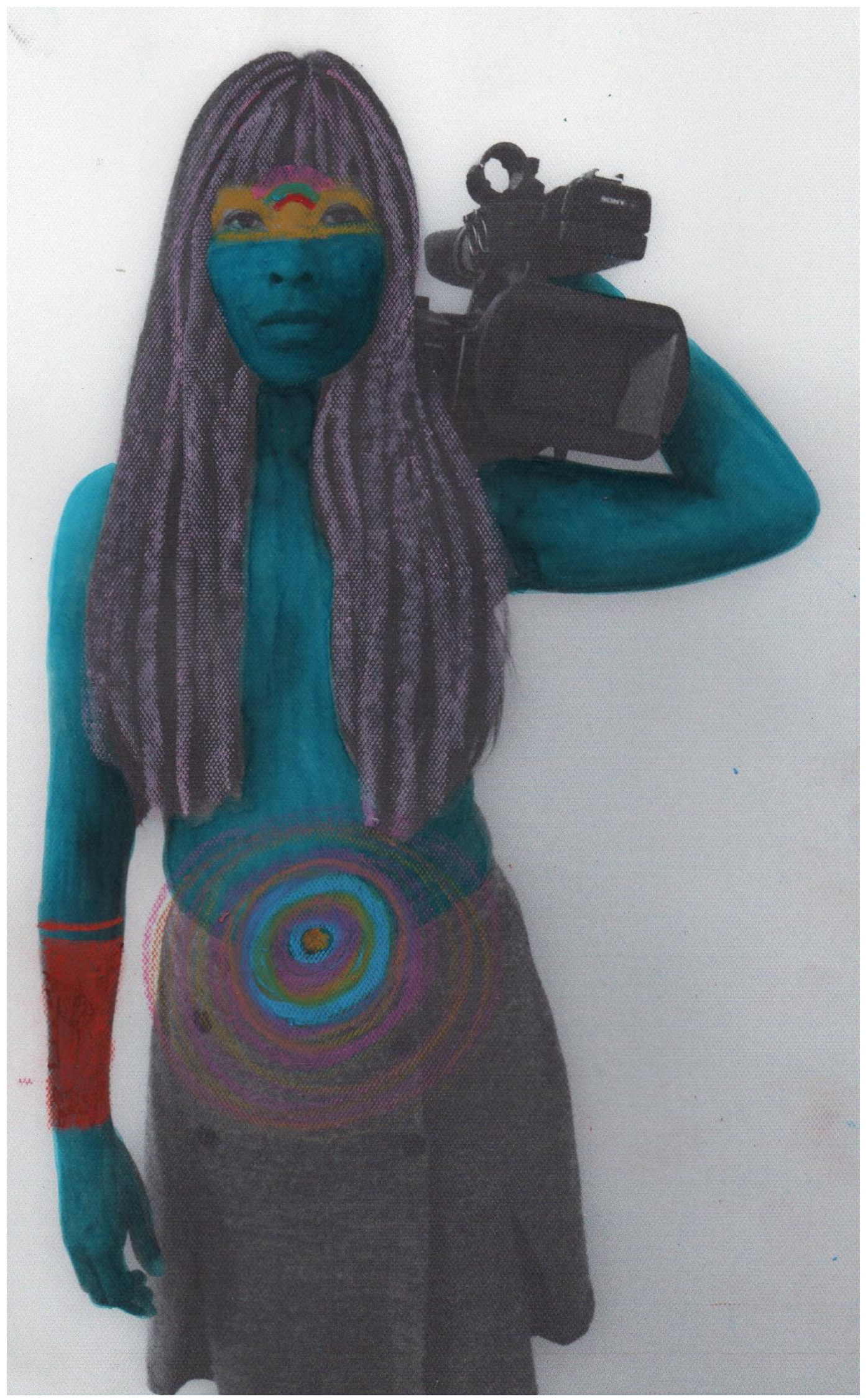

“seres sem umbigo” 


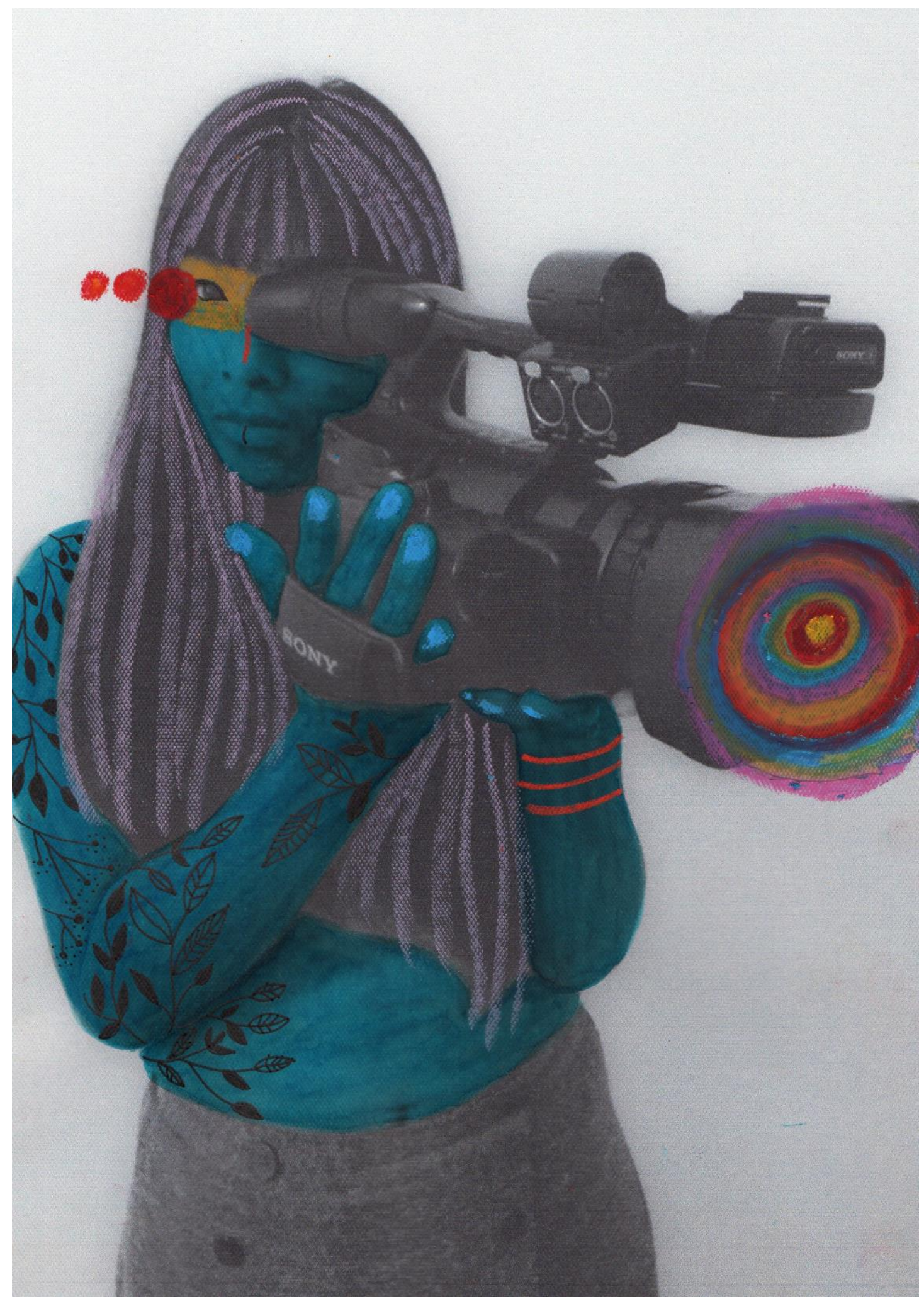

"cosmo visão" 


\section{Referências}

SPIVAK, Gayatri C.The Post-Colonial Critic: Interviews, Strategies, Dialogues. Edited by Sarah Harasym. New York: Routledge, 1990.

MULVEY, Laura. Visual Pleasure and Narrative Cinema. Screen, v. 16, n. 3, p. 6-27, Autumn 1975.

BENTES, Ivana. Câmera muy very good pra mim trabalhar. Disponível em: < http://www.videonasaldeias.org.br/2009/biblioteca.php?c=11 . Acessado em 23 de Setembro de 2014.

GEERTZ, Clifford. O saber local: novos ensaios em antropologia interpretativa. Petrópolis, RJ. Ed. Vozes, 1997.

TURNER, Terence. 1993. De Cosmologia a História: resistência, adaptação e consciência social entre os Kayapó. In E. Viveiros de Castro e M. Carneiro da Cunha (orgs.). Amazônia: Etnologia e História Indígena. São Paulo: NHII/USP/ FAPESP. pp. 43-66.

Recebido em: 30/01/2017.

Aprovado em: 13/04/2017. 